\title{
Identification and Characterization of Different Types of Plastics Wastes Using X-Ray Diffraction and $\mathrm{X}$-Ray Fluorescence Techniques
}

\author{
Shawbo A. Abubaker, Faten A. Chaqmaqchee and Akram H. Taha \\ Department of Physics, Faculty of Science and Health, Koya University, Koya KOY45, Kurdistan Region-F.R. Iraq
}

\begin{abstract}
In this study, different types of polymers in postconsumer plastics with pure plastics have been studied. Highdensity polyethylene (HDPE1 and HDPE2), polyvinyl chloride (PVC3 and PVC4), polyethylene terephthalate (PET5 and PET6), and polypropylenes (PP7 and PP8) were compared using X-ray diffraction (XRD) and X-ray fluorescence (XRF) techniques. XRF has shown the spectral in K-lines of polymer materials present in plastics waste. The peak intensity and degree of crystallinity of commercial polymers are varied using XRD analysis. The intensity not attributable to the crystalline peaks may be regarded as the amorphous scattering and used as a template in analyzing the diffraction pattern of the samples. The XRD analysis helps to provide characteristic spectral lines whose intensities vary with the type of each constituent polymer. The combined usage of XRD and XRF techniques yielded very useful and effective results for a commercial plastic management.
\end{abstract}

Index Terms-Commercial plastics; mass concentrations; polymers X-ray diffraction; X-ray fluorescence.

\section{INTRODUCTION}

Humans in daily life have benefited from the use of polymers compared with other materials. Polymers are amongst the most important materials with relatively good mechanical and physical properties, which applied to a wide variety of applications (Andrady and Neal, 2009). Plastics are one of the most used materials in the world due to variety of applications such as furniture, clothes, building materials, and automotive components. Plastics have replaced a wide range of traditional materials including glass, steel, wood, and even concrete. According to the chemical structure and processing, plastics are varying their applicability, due to a range of desirable properties such as low density and resistance to a wide range of chemicals (Siddiqui, et al., 2008; Tadayyon, Zebarjad and Sajjadi, 2012). There are important factors contributing

ARO-The Scientific Journal of Koya University

Vol. IX, No.2 (2021), Article ID: ARO.10840, 4 pages

DOI: $10.14500 /$ aro. 10840

Received 11 July 2021; Accepted: 25 September 2021

Regular research paper: Published 28 October 2021

Corresponding author's, e-mail: shawbo.abdulsamad@koyauniversity.org

Copyright (C) 2021 Shawbo A. Abubaker, Faten A. Chaqmaqchee and

Akram H. Taha.. This is an open access article distributed under the

Creative Commons Attribution License. the rapid growth of manufacturing and usage of polymeric plastics such as low cost, weigh less, high strength, design flexibility for any shape, and good esthetic goodness. These plastics are generally produced from fossil fuels (Kwong, et al., 2004; Lobo and Bonilla, 2003), and by extending range of products with using plastics continuously, the plastic waste causing pollution. However, with these severe rises in the use of plastic materials, identical development of processes for the harmless degradation of the plastic waste has not been noticed. Recycling of plastic waste has become one of the solutions compared with other materials, due to the full identification and characterization of collected plastics can be a formidable challenge, however, the cost of recycling is high and the recycled products have lower qualities (Chaqmaqchee, Baker and Salih, 2017). Nowadays, polyethylene terephthalate (PET) is the most common plastic and has significant applications in industry such as drug and food packaging (Han, 2019). PET accounts for roughly $40 \%$ of all plastic made in the world (Andrady and Neal, 2009; Alnaimi, Elouadi, and Kamal, 2015). Among all PET types, high-density polyethylene (HDPE) contains carbon and hydrogen as fundamental elements. It also has stronger intermolecular forces with higher tensile strength than PET (Prasad, De and De, 2011). Physically, it is harder, opaquer, with a high degree of crystalline structure that can resist somewhat higher temperatures with extensive industrial applications. For example, HDPE pipes are used to carry potable water, waste water, cables, and transportation of oil and compressed gases (Tadayyon, Zebarjad and Sajjadi, 2012). In addition, polypropylene (PP) is widely used in many fields, including floor coverings, automobiles, building materials, electronics and electric materials, wall coverings (Singh, et al., 2017). However, poor thermal stability and fire resistance of PP limit the status and range of its practical application (Sajwan, Singh and Aggarwal, 2007). Among the different commodity polymers, polyvinyl chloride (PVC) is a versatile and most extensively used along with polyethylene due to its industrial applications and academic interests. PVC has many applications in construction, medicine, window, and door (Wang, Zhang and Zhou, 2017; Pan, et al., 2004).

The aim of this study is to characterize different types of plastics including HDPE (HDPE1 and HDPE2), PVC (PVC3 and PVC4), PET (PET5 and PET6), and PPs (PP7 and PP8). $\mathrm{X}$-ray diffraction (XRD) and X-ray fluorescence (XRF) 
techniques were used as relative ease of use, fast sample preparation and analysis, minimal recalibration, a broad range of detectable elements, and a broad concentration range for analysis. The morphological features of semi-crystalline polymers such as crystalline level and crystal thickness are mainly decided by the nature of the polymer. Thus, XRD and XRF are two successful techniques for performing material analysis without changing structure avoid any damage, nondestructive, and exact qualitative and quantitative analysis and suited for real-world plastics recycling environments (Kubala-Kuku, et al., 2013).

\section{Materials AND Methods}

The morphological features of semi-crystalline polymers such as crystalline level and crystal thickness are mainly decided by the nature of the polymer. XRD and XRF are two successful techniques for performing material analysis (Sabri, 2020) without changing structure, avoid any damage, non-destructive, and exact qualitative and quantitative analysis. Four pure polymer materials of around $11 \mathrm{~g}$ of HDPE1, PVC1, PET1, and PP1 and four commercial plastics of size $2 \times 2 \mathrm{~cm}^{2}$ of HDPE2, PVC2, PET2, and PP2 have been collected from different companies of Erbil and Sulaymaniyah in the Iraqi Kurdistan region. XRD technique was used to determine the peak position and it is operating at $45 \mathrm{kV}$ and $40 \mathrm{~mA}$ and can perform various analyses from phase identification and quantification to determine the phases and the morphological properties of the sample and to compare of complex chemical materials structures (Song, et al., 2016).

In addition, the bonding nature of plastics can be analyzed using XRF technique, which is an effective approach to distinguish plastic sorting quantitative and the elemental concentration and their emitted energies for all plastics samples. All measurements were carried out under vacuum, using a Rigaku NEX CG with RX9, $\mathrm{Mo}, \mathrm{Cu}$, and $\mathrm{Al}$ targets. Chemical elements with a high and a low concentration were detected with the samples. The XRF $\mathrm{K}^{\alpha}$ and $\mathrm{K}^{\beta}$ line intensities were measured for the all eight samples' elements, in which the applied voltage increased in general with the required lines energies. The X-ray measuring time was only $200 \mathrm{~s}$ for the $\mathrm{Al}$ target and $100 \mathrm{~s}$ for the other targets. X-rays from the X-ray tube pass through an optional filter on their way to the samples that placed in the chamber and measured by $20 \mathrm{~mm}$ diaphragm in vacuum. The $\mathrm{X}$-rays then travel from the sample to the detector, which is cooled electrically. The signal is then processed by electronics and sent to a computer program, where the chemical compositions and intensity versus energy are measured.

\section{RESULTS AND DisCUSSION}

Structural analysis of pure HDPE1, PVC1, PET1, and PP1 and commercial HDPE2, PVC2, PET2, and PP2 was carried out by XRD analytical under $45 \mathrm{kV} / 40 \mathrm{~mA}-\mathrm{X}$-ray,

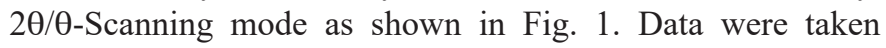

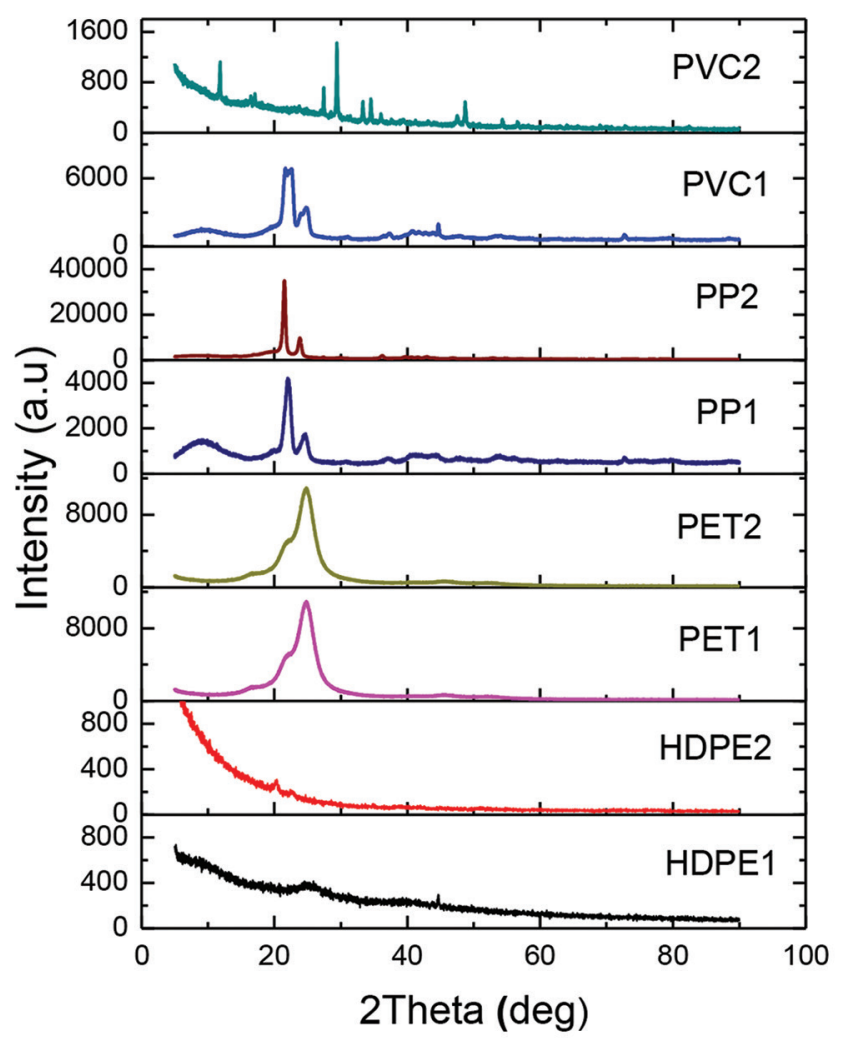

Fig. 1. A compression X-ray diffraction spectra of pure high-density polyethylene (HDPE), polyethylene terephthalate (PET), polypropylenes (PP), and polyvinyl chloride (PVC) with commercial HDPE, PET, PP, and PVC polymers.

for the $2 \theta$ range of $0-90^{\circ}$ with a step of $0.012^{\circ}$. The XRD spectra of HDPE1, HDPE12 and PET1, PET 2 polymers have not shown large distinguishable differences. However, PP1, PP2 and PET1, PET2 show different characteristic, this is due to the amount of elements added during production. For each polymer, a unique spectral line of XRD is available for identification. The XRD pattern of HDPE that taken from water pipe as sample is based on the spectral line near $2 \theta=25^{\circ}$. The analysis crystal structure indicates that the HDPE is orthorhombic structure, monoclinic and hexagonal, depending on the processing conditions. Some small peaks are also apparent at angles larger than $40^{\circ}$ (Hasan, Banerjee and Lee, 2015). For the PET1, a broad peak at the $2 \theta=24.8^{\circ}$ was observed, which clearly shows its poor crystallinity due to the high integrated area, while the XRD patterns for PET2, have $2 \theta$ in the range of $20-25^{\circ}$, one strong peak operating at $24.8^{\circ}$ and one moderately peak at $22.02^{\circ}$. For pure PP 1 , the amorphous nature has a broad peak in the region of $10-25^{\circ}$, whereas for PP2 has more intensive peak at around $21.49^{\circ}$, hence more crystalline. In addition, the maximum peak of pure PVC1 was around $22.02^{\circ}$. The PVC2 that taken from door as sample shows more peaks compared to the pure PVC1 due to the addition of different amount elements to it. The intensity and the width of each peak are different, depending on the samples. These peaks are due to XRD from the superimposed on a broad region of intensity which results from the amorphous component of the polymer (polymers 


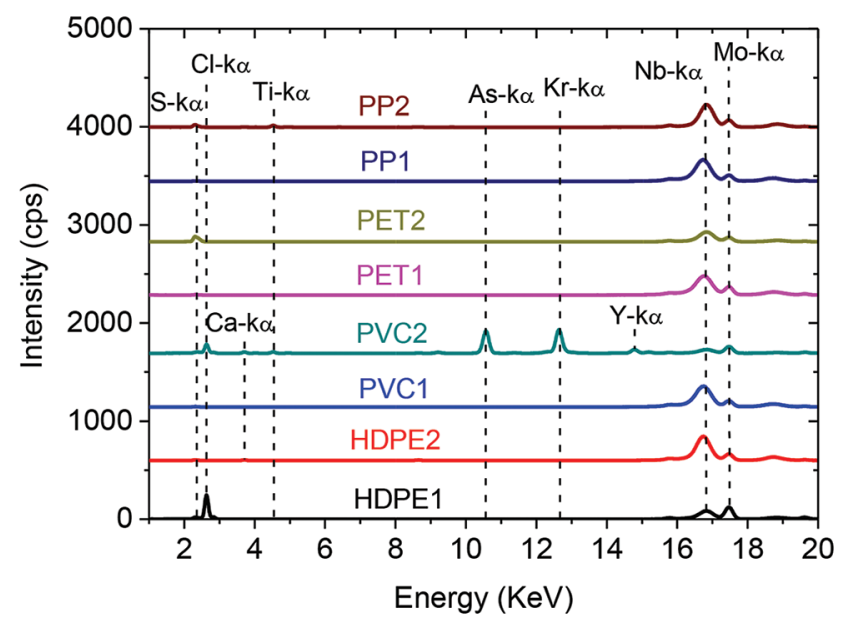

Fig. 2. Intensity versus energy for various pure polymers (high-density polyethylene [HDPE1], polyvinyl chloride [PVC1], polyethylene terephthalate [PET1], and polypropylenes [PP1]) and commercial plastics (HDPE2, PVC2, PET2, and PP2) calculated over the energy range from 1 to $20 \mathrm{KeV}$ using $\mathrm{XRF}$ with $\mathrm{RX} 9, \mathrm{Mo}, \mathrm{Cu}$, and $\mathrm{Al}$ targets.

are usually not $100 \%$ crystalline) (Kwong, et al., 2004). In Table 1, the peak intensity and crystalline size for each maximum peak have been estimated using Debye-Scherrer formula (Lin, et al., 2005; Mote, Purushotham and Dole, 2012; Parvin, et al., 2013).

$t=\frac{0.9 »}{\beta \cos \theta}$

Where, $\lambda, \beta, \theta$, and $\mathrm{t}$ are the wavelength of X-ray $(1.5406 \AA)$, the full width at half maximum, the diffraction angle, and the particle diameter size, respectively.

Rigaku NEX CG XRF spectrometer analyses were used to determine HDPE1, PVC1, PET1, and PP as well as the commercial plastics HDPE2, PVC2, PET2, and PP2. When these samples are irradiated with X-rays, the intensity as a function of energy can be calculated over the energy range of $1-40 \mathrm{keV}$ at the same computing conditions. Fig. 2 shows the peaks in the ranges of $2.65,4.51,10.58,12.63,14.79$, 16.83, and $17.48 \mathrm{keV}$ corresponding to $\mathrm{S}-\mathrm{k} \alpha, \mathrm{Cl}-\mathrm{k} \alpha, \mathrm{Ca}-\mathrm{k} \beta$, Ti-k $\alpha$, As-kr, Nb-k $\alpha$, and Mo-k $\alpha$ lines. It shows clearly that the highest peak intensities appear with Cl-k $\alpha$ line in HDPE1 of pure sample, and with As-k $\alpha$ and $\mathrm{Kr}-\mathrm{k} \alpha$ lines in PVC2 of door sample, and finally with $\mathrm{Nb}-\mathrm{k} \alpha$ line for almost all the eight samples.

Furthermore, the chemical compositions for four polymer samples of HDPE1, PVC1, PET1, and PP1 underwent analysis, along with four commercial plastics samples of HDPE2, PVC2, PET2, and PP2 using XRF. The raw and processed data are listed in Table 2, where the elements are distributed in the random samples. The total percentages of the eight samples were less and more than $100 \%$ due to the statistical errors during measurements. Element of $\mathrm{Cl}$ appears with high mass percentage at around 53.9 and $93.2 \mathrm{Mg} / \mathrm{cm}^{2}$ in HDPE1 and PVC2, respectively, whereas other elements appear with low mass concentration, and has good agreement with Fig. 2. The mass concentration of propene PP appears to be high in the six samples, which is highly hazardous in daily use. PP has a good
TABLE I

Intensity, Crystalline Size, And D Spacing of the Most Intense Peak of THE SAMPLES

$\overline{2 \boldsymbol{\theta} \text { o of the intense peak pure Intensity (cps) FWHM }\left(^{\circ}\right) \text { Crystalline size }(\AA)}$ polymer

\begin{tabular}{lccc}
\hline 25.33 (HDPE1) & 392.4926 & 0.614 & 2.5 \\
24.688 (PET1) & $10,751.261$ & 0.80 & 1.90 \\
21.949 (PP1) & 3346.55 & 0.358 & 4.17 \\
21.54 (PVC1) & 5312.01 & 0.179 & 8.32 \\
\hline \hline
\end{tabular}

FWHM: Full width at half maximum, HDPE: High-density polyethylene,

PET: Polyethylene terephthalate, PP: Polypropylenes, PVC: Polyvinyl chloride

TABLE II

XrF Measurements for Elements of Plastics (\%), Where the Totals $100 \% \pm 0.05$ STATISTICAL ERRORS

\begin{tabular}{|c|c|c|c|c|c|c|c|c|c|}
\hline \multirow{2}{*}{\multicolumn{2}{|c|}{ No. Elements }} & \multicolumn{8}{|c|}{ Plastics mass concentration $\% \mathrm{Mg} / \mathrm{cm}^{2}$} \\
\hline & & HDPE1 & HDPE2 & PVC1 & PVC2 & PET1 & PET2 & PP1 & PP2 \\
\hline 1 & $\mathrm{Cl}$ & 53.9 & 0.018 & 0.0072 & 93.2 & 0.0030 & 0.0012 & 0.0515 & 0.0218 \\
\hline 2 & $\mathrm{pp}$ & 45.7 & 99.7 & 99.8 & -- & 99.8 & 100.0 & 99.7 & 99.7 \\
\hline 3 & $\mathrm{Si}$ & 0.273 & -- & 0.0478 & 0.877 & 0.0212 & 0.0037 & 0.0275 & 0.0284 \\
\hline 4 & $\mathrm{P}$ & 0.103 & 0.001 & 0.0047 & 0.293 & 0.0012 & 0.0015 & 0.0 & 0.0050 \\
\hline 5 & $\mathrm{Ca}$ & 0.0510 & 0.213 & 0.0161 & 2.73 & 0.0025 & 0.0023 & 0.0150 & 0.0453 \\
\hline 6 & $\mathrm{Sn}$ & 0.0065 & 0.0025 & 0.0046 & 0.0021 & 0.0066 & 0.0006 & 0.0042 & 0.0012 \\
\hline 7 & $\mathrm{Ti}$ & 0.0037 & 0.0215 & 0.0004 & 1.38 & -- & -- & 0.0003 & 0.146 \\
\hline 8 & V & 0.0025 & -- & -- & -- & -- & -- & -- & -- \\
\hline 9 & $\mathrm{Fe}$ & 0.0024 & 0.0014 & -- & 0.0057 & -- & 0.0003 & -- & 0.0006 \\
\hline 10 & $\mathrm{Cu}$ & 0.0008 & 0.0005 & 0.0002 & -- & 0.0001 & 0.0001 & 0.0002 & 0.0001 \\
\hline 11 & $\mathrm{Br}$ & 0.0002 & 0.0001 & -- & -- & -- & -- & -- & -- \\
\hline 12 & $\mathrm{~S}$ & -- & 0.0248 & 0.0152 & 0.439 & 0.0181 & 0.0023 & 0.0174 & 0.0031 \\
\hline 13 & $\mathrm{Al}$ & -- & 0.0107 & 0.0261 & -- & 0.0098 & -- & 0.0189 & 0.0477 \\
\hline 14 & $\mathrm{Zn}$ & -- & 0.0028 & -- & 0.0073 & -- & -- & 0.0001 & 0.0009 \\
\hline 15 & $\mathrm{~K}$ & -- & 0.0007 & 0.0019 & -- & 0.0006 & -- & 0.0018 & -- \\
\hline 16 & $\mathrm{~Pb}$ & -- & 0.0004 & -- & 0.992 & -- & -- & -- & -- \\
\hline 17 & $\mathrm{Cr}$ & -- & 0.0001 & 0.0007 & -- & -- & -- & -- & 0.0001 \\
\hline 18 & $\mathrm{Mg}$ & -- & -- & 0.0652 & -- & 0.0890 & -- & 0.122 & -- \\
\hline 19 & $\mathrm{Bi}$ & -- & -- & -- & 0.0051 & -- & -- & -- & -- \\
\hline 20 & Y & -- & -- & -- & 0.0038 & -- & -- & -- & -- \\
\hline 21 & $\mathrm{Sr}$ & -- & -- & -- & 0.0013 & -- & -- & -- & -- \\
\hline 22 & $\mathrm{Sb}$ & -- & -- & -- & -- & 0.0438 & 0.0050 & -- & -- \\
\hline 23 & $\mathrm{Co}$ & -- & -- & -- & -- & 0.0003 & 0.0003 & -- & -- \\
\hline 24 & $\mathrm{Mn}$ & -- & -- & -- & -- & -- & 0.0001 & -- & -- \\
\hline 25 & Hf & -- & -- & -- & -- & -- & 0.0001 & -- & 0.0001 \\
\hline
\end{tabular}

FWHM: Full width at half maximum, HDPE: High-density polyethylene,

PET: Polyethylene terephthalate, PP: Polypropylenes, PVC: Polyvinyl chloride, X-ray fluorescence

chemical and heat resistance and can be used in household and industrial applications (Chen, et al., 2020).

\section{Conclusion}

In this study, we demonstrated the application of XRD and XRF for the identification of various types of plastics presented in the waste that is dangerous to the health and the environment. The robustness of these techniques was explained by reliable and repeatable results analyzed for different polymers. The XRD analysis indicated that both pure polymers and plastic wastes have amorphous nature. The structure of commercial plastics as examined by the XRD technique reveals different materials added to the pure polymers in which confirmed the presence by XRF 
techniques. The existence of additional peaks at various diffraction angles in XRD spectra of plastic wastes is due to variation in the crystallization during the manufacturing procedure, diverse additives, and their ratio in the sample. Results show that containing different elements effectively improved the crystallization properties of PVC2, PP2, without changing the crystalline structure of them. However, in plastics production elements such as chloride, ethylene dichloride, lead, cadmium, and other toxic chemicals were observed in most of them. Commercial PVC shows the higher ratio of $\sim 0.992$ lead and $\sim 2.73$ cadmium, which is widely known as the most toxic elements that cause health problems for human and animal health and environment as a whole. It can also be concluded that the XRD and XRF studies of HDPE1, PP1, PET1, PVC1 and HDPE2, PP2, PET2, PVC2 that acquired from different manufacturer reveal their prominent forensic characterization future. The combined uses of XRD and XRF techniques have excellent potential for rapid identification and analysis of plastics as well as they are benefit for recycling and management of plastic waste.

\section{ACKNOWLEDGMENT}

The authors gratefully acknowledge the Department of Physics, Faculty of Science and Health at Koya University for enabling this study.

\section{REFERENCES}

Alnaimi, S., Elouadi, B. and Kamal. I., 2015. Structural, thermal and morphology characteristics of low density polyethylene produced by QAPCO. In Proceedings of the $8^{\text {th }}$ International Symposium on Inorganic Phosphate Materials, Agadir, Morocco.

Andrady, A.L. and Neal, M.A., 2009. Applications and societal benefits of plastics. Philosophical Transactions of the Royal Society B: Biological Sciences, 364(1526), pp.1977-1984.

Chaqmaqchee, F.A.I., Baker, A.G. and Salih, N.F., 2017. Comparison of various plastics wastes using X-ray fluorescence. American Journal of Materials Synthesis and Processing, 2(2), pp.24-27.

Chen, D.M.C., Bodirsky, B.L., Krueger, T., Mishra, A. and Popp, A., 2020. The world's growing municipal solid waste: Trends and impacts. Environmental Research Letters, 15, pp.1-12.

Han, M., 2019. Depolymerization of PET bottle via methanolysis and hydrolysis. In: Recycling of Polyethylene Terephthalate Bottles, William Andrew Publishing, Burlington, MA, pp.85-108.

Hasan, M., Banerjee, A.N. and Lee, M., 2015. Enhanced thermo-mechanical performance and strain-induced band gap reduction of $\mathrm{TiO}_{2} @ \mathrm{PVC}$ nanocomposite films. Bulletin of Materials Science, 38(2), pp.283-290.
Kubala-Kukuś, A., Ludwikowska-Kẹdzia, M., Banaś, D., Braziewicz, J., Majewska, U., Pajek, M. and Wudarczyk-Moćko, J., 2013. Application of the $\mathrm{X}$-ray fluorescence analysis and X-ray diffraction in geochemical studies of the Pleistocene tills from Holy Cross Mountains. Radiation Physics and Chemistry, 93, pp.92-98

Kwong, C., Choy, W.C.H, Djurišić, A.B, Chui, P.C., Cheng, K.W. and Chan, W.K., 2004. Poly (3-hexylthiophene): $\mathrm{TiO}_{2}$ nanocomposites for solar cell applications. Nanotechnology, 15(9), p.1156.

Lin, Y., Du, W., Tu, D., Zhong, W. and Du, Q., 2005. Space charge distribution and crystalline structure in low density polyethylene (LDPE) blended with high density polyethylene (HDPE). Polymer International, 54(2), pp.465-470.

Lobo, H. and Bonilla, J.V., 2003. General introduction to plastics analysis. Plastics Engineering New York, 68, pp.1-42.

Mote, V., Purushotham, Y. and Dole, B., 2012. Williamson-Hall analysis in estimation of lattice strain in nanometer-sized $\mathrm{ZnO}$ particles. Journal of Theoretical and Applied Physics, 6(1), pp.1-8.

Pan, M., Shi, X., Li, X., Hu, H., Zhang, L., 2004. Morphology and properties of PVC/clay nanocomposites via in situ emulsion polymerization. Journal of Applied Polymer Science, 94(1), pp.277-286.

Parvin, N., Ullah, M.S., Mina, M.F.G. and afur, M.A., 2013. Structures and mechanical properties of talc and carbon black reinforced high density polyethylene composites: Effects of organic and inorganic fillers. Journal of Bangladesh academy of Sciences, 37(1), pp.11-20.

Prasad, S.G., De, A. and De, U., 2011. Structural and optical investigations of radiation damage in transparent PET polymer films. International Journal of Spectroscopy, 2011, p.810936.

Sabri, M.M, 2020. Chemical and structural analysis of rocks using X-ray fluorescence and X-ray diffraction techniques. ARO The Scientific Journal of Koya University, 8(1), pp.79-87.

Sajwan, M.B., Singh, R. and Aggarwal, S., 2007. Characterization of plastic pipes by X-ray diffraction in forensic analysis. Indian Journal of Criminology and Criminalistics, 28, pp.76-81.

Siddiqui, M.N., Gondal, M.A. and Redhwi, H.H., 2008. Identification of different type of polymers in plastics waste. Journal of Environmental Science and Health, Part A, 43(11), pp.1303-1310.

Singh, N., Hui, D., Singh, R., Ahuja, I.P.S., Feo, L. and Fraternali, F., 2017. Recycling of plastic solid waste: A state of art review and future applications. Composites Part B: Engineering, 115, pp.409-422.

Song, W., Sun, Z., Zhang, D., Han, B., He, L., Wang, X. and Lei, Q., 2016. Synthesis and characterization of low density polyethylene with multiferroic bismuth ferrite nanocomposite. Journal of Materials Science: Materials in Electronics, 27(3), pp.2328-2334.

Tadayyon, G., Zebarjad, S.M. and Sajjadi, S.A., 2012. Effect of both nano-size alumina particles and severe deformation on polyethylene crystallinity index. Journal of Thermoplastic Composite Materials, 25(4), pp.479-490.

Wang, L., Zhang, M. and Zhou, B., 2017. Thermal stability, combustion behavior, and mechanical property in a flame-retardant polypropylene system. Applied Sciences, 7(1), p.55. 